\title{
A aplicaçáo da terapia comunitária na intervençáo com adolescentes: novas estratégias de prevenção e promoção ${ }^{1}$
}

\author{
Flávia Cristina Zago ${ }^{a}$, Ana Cláudia Pinto Bredariol ${ }^{b}$, Danielisson Paulo de Mesquita ${ }^{\mathrm{c}}$
}

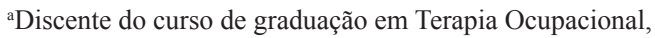 \\ Universidade de Uberaba - UNIUBE, Uberaba, MG, Brasil \\ ${ }^{\text {b}}$ Docente do curso de graduação em Terapia Ocupacional, \\ Universidade Federal do Triângulo Mineiro - UFTM, Uberaba, MG, Brasil \\ Doutora em Educação Especial, Universidade Federal de São Carlos - UFSCar, São Carlos, SP, Brasil \\ 'Docente do curso de graduação em Terapia Ocupacional, \\ Universidade de Uberaba - UNIUBE, Uberaba, MG, Brasil. Especialista em Educação Especial, \\ Universidade Federal de Uberlândia - UFU, Uberlândia, MG, Brasil
}

\begin{abstract}
Resumo: Diante da vulnerabilidade do adolescente frente às transformações e resistências, o trabalho em grupo utilizado pela Terapia Ocupacional através de técnicas e dinâmicas favorece a expressão, controle da ansiedade e a maturidade biopsicossocial na intervenção. Atualmente, uma estratégia utilizada com adolescentes é a terapia comunitária (TC) por ser um espaço de acolhimento onde todos são iguais e compartilham seus sofrimentos, afinidades e ansiedades. Assim, este estudo analisou a eficácia das atividades grupais utilizadas na Terapia Ocupacional como estratégias do aquecimento nas rodas de terapia comunitária. Participaram desta pesquisa 11 adolescentes com idade entre 12 e 14 anos. A pesquisa foi realizada no município de Uberaba, MG, em uma instituição social, que visa o apoio à infância e juventude, e utilizou como instrumento de coleta de dados filmagem, fotos e registro manuscrito durante a aplicação de 12 estratégias divididas em três categorias: competição, cooperação e autoconhecimeto/autoestima aplicados no aquecimento da roda de TC. Os dados do material coletado foram analisados e apresentados através do recurso de quadro para melhor visualização e compreensão do comportamento dos adolescentes durante o aquecimento e a roda de TC. Como resultados obtidos: disputa, agitação, desatenção e sociabilidade, comportamentos condizentes à fase da adolescência pelas diversas mudanças, alterações emocionais e busca da identidade. A partir dos resultados da pesquisa, foi possível observar que os comportamentos desencadeados possuem relação direto-indireta com as estratégias utilizadas e que estas são facilitadoras no desenvolvimento da discussão dos temas abordados nas rodas de TC.
\end{abstract}

Palavras-chave: Adolescente, Terapia Ocupacional, Comportamento do Adolescente.

\section{Community therapy application in intervention with adolescents: new strategies for prevention and promotion}

\begin{abstract}
Given adolescents' vulnerability facing transformations and resistances, the group work used by Occupational Therapy through techniques and dynamics favors expression, anxiety control and biopsychosocial maturity in intervention. Currently, one strategy used with teenagers is Community Therapy (CT), because it provides a welcoming environment where all are equal and can share their sufferings, anxieties and affinities. Thus, this study examined the effectiveness of group activities used in occupational therapy as warm up
\end{abstract}

Autor para correspondência: Flávia Cristina Zago, Universidade de Uberaba, Av. Nenê Sabino, 1801. Universitário, CEP 38055-500, Uberaba, MG, Brasil, e-mail: flaviazago.to@gmail.com

Recebido em 31/5/2011; Revisão em 1/6/2012; Aceito em 18/3/2013. 
strategies in Community Therapy circles. Eleven teenagers aged 12 to 14 years old participated in the research. The study was carried out in a social institution that aims to support children and youth in the municipality of Uberaba, Minas Gerais state. Video and photo images and handwritten records were used as data collection instruments during the application of the 12 strategies, divided into three categories: competition, cooperation, and self-knowledge/self-esteem, applied for warming up the CT circles. Data were analyzed and presented through the use of a chart for better visualization and understanding of the adolescents' behavior during the warm up CT circles. The results obtained showed dispute, unrest, lack of attention and sociability; behaviors that are inherent to adolescence due to the several changes, emotional alterations and search for identity that these subjects experience. Based on the survey results, it was possible observe that the behaviors have triggered direct-indirect relationship with the strategies used as facilitators in the discussion development regarding the issues addressed in the CT circles.

Keywords: Adolescent, Occupational Therapy, Adolescent Behavior.

\section{Introdução}

A adolescência é um período que requer atenção por ser um momento de transição em que o adolescente sente-se vulnerável às transformaçóes e, muitas vezes, resistente a novas idéias e informaçóes. Por isso, vem se intensificando e modificando a forma de intervir com essa população. Segundo o Estatuto da Criança e do Adolescente em seu Art. $2^{\circ}$ que "Considera-se criança, para os efeitos desta Lei, a pessoa até doze anos de idade incompletos, e adolescente aquela entre doze e dezoito anos de idade." (BRASIL, 1990, p. 02).

No período da adolescência, é importante reforçar a autovalorização e a maturidade biopsicossocial para que a ampliação dos espaços e a emancipaçáo pessoal possam acontecer. Na Terapia Ocupacional, o trabalho em grupo busca através de técnicas e dinâmicas amadurecer os elementos que constituem a estruturação da identidade pessoal ao intervir com o adolescente.

Segundo Ballarin (2007), o grupo apresenta um potencial terapêutico que favorece a expressáo e a gratificação de ansiedades, e para desenvolver este trabalho faz uso de técnicas e dinâmicas de grupo a fim de estabelecer o vínculo com a população assistida, assim como a terapia comunitária que faz uso de alguns desses recursos utilizados nas intervençôes terapêuticas ocupacionais no momento do aquecimento em suas rodas de grupo, como forma de aproximaçáo dos membros da roda.

As estratégias de grupo utilizadas no aquecimento das rodas de terapia comunitária, de acordo com Andrade (2007), buscam o resgate da autoestima, auxiliam na tomada de decisóes e no compartilhar das emoçôes, descobrindo seus valores e capacidades frente à sociedade. Fundamental para o adolescente dinamizar as relaçóes sociais, através do diálogo e da reflexão, permitindo ir além do unitário para atingir o comunitário.

Com isso, atualmente, a terapia comunitária (TC) tem sido uma das estratégias utilizadas pelos profissionais, entre eles o terapeuta ocupacional para promover o resgate e o apoio aos adolescentes, principalmente aqueles em situação de risco, pois, como define Barreto (2008), a terapia comunitária (TC) é um espaço de acolhimento para partilhar a sabedoria, sofrimentos, afinidades, e acrescento angústias e ansiedades, de forma circular partindo do princípio da horizontalidade. Esse tipo de intervenção possibilita que o adolescente se sinta protegido e seguro, em um ambiente que é fora do seu contexto diário e com pessoas diferentes das de sua rede social.

Por ser a terapia comunitária (TC) desenvolvida de forma circular e partindo do principio da horizontalidade - onde todos são iguais, não existindo hegemonia entre os participantes, o adolescente enriquece as discussões contribuindo com suas dúvidas e anseios ao trazer para a roda sentimentos que em outras situaçóes se sentiria constrangido em expor. O terapeuta ocupacional faz uso dessa abordagem diferenciada proporcionada pelas rodas de terapia comunitária como um facilitador, uma vez que é por meio dessa atividade que se realizam as intervençôes.

Segundo Barreto (2008, p. 38), "a terapia comunitária é um espaço de acolhimento” que proporciona para o adolescente um ponto de referência, ao despertar a segurança e o apoio, pois 
[...] com todas essas transformaçóes o adolescente vive uma intensa busca por sua identidade que acarreta angústia, dificuldade de relacionamento, confusão e medo (ZAGURY, 2000, p. 27).

De acordo com Barreto (2008), a TC é dividida em seis etapas, sendo elas: o acolhimento, a escolha do tema, a contextualização, a problematização, os rituais de agregação e conotação positiva e a avaliação. No momento do acolhimento, são utilizadas algumas estratégias, como música, dinâmicas, dramatização e atividades grupais, como forma de aquecer o corpo para o desenvolvimento da roda.

$\mathrm{O}$ acolhimento tem a proposta, segundo o autor supracitado, de criar um clima de grupo e deixar os participantes mais descontraídos e à vontade, de "quebrar o gelo". É o momento em que acontecem exercícios ou brincadeiras que podem ser propostos por algum participante ou pelo coterapeuta que irá auxiliar no desenvolvimento da roda.

As estratégias utilizadas na etapa do acolhimento têm por objetivo reforçar e valorizar a autoestima e autoconfiança dos envolvidos nesse processo; ao trabalhar as inseguranças e ansiedades desses adolescentes, ocorrerá um significativo aumento da valorização e confiança frente às tomadas de decisôes.

É neste momento que se faz necessário que o adolescente sinta-se estruturado emocionalmente para exercitar os conceitos constituídos de resiliência, que Assis et al. (2008) relatam ser

“[...] um atributo emocional que o indivíduo tem ao superar as adversidades [...]", ou seja, para resistir às consequências negativas das situaçóes de risco e desenvolvê-las adequadamente, ao ser um adolescente resiliente valorizará os vínculos de apoio e estímulo.

A TC é um espaço de promoção da resiliência, pois, através da partilha de experiência de vida, os indivíduos reforçam a autoestima, fortalecem os vínculos interpessoais, bem como estimulam a autonomia. (BARRETO, 2008, p. 38).

Para o adolescente, esse momento é de extrema importância, por ser um período de situaçóes transformadoras, em que os mesmos se deparam constantemente com momentos de vulnerabilidade - que para Assis et al. (2008) "[...] são predisposiçóes a que o indivíduo está suscetível a desenvolver psicopatologias e problemas de comportamento ao surgir um resultado negativo [...]", acrescento ainda os desvios de conduta como consequência da vulnerabilidade, fato frequente na adolescência.
Diante de tantos conflitos existentes nesse momento de transição, como assim salienta o Ministério da Saúde (BRASIL, 2005), faz-se necessário focar na mediaçáo da resiliência dos adolescentes para que se consigam reverter os índices que envolvem a populaçáo em questáo em situaçôes de desvios de conduta e violências afins, como envolvimento com o tráfico, homicídios e assaltos e que não sejam propagadores dos tristes índices, assim como vítimas.

Espera-se que este estudo ofereça subsídios e uma nova visão aos profissionais, principalmente aos terapeutas ocupacionais ao fazer uso desse método de intervenção, disseminar e multiplicar a TC entre os adolescentes e compreender melhor o seu mundo ao falar a mesma linguagem, pois é uma população que necessita de redes de apoio para náo estar vulnerável a situaçóes conflitantes.

Por fim, destaca-se a importância do trabalho para o desenvolvimento de intervençóes voltadas à realidade dessa população, pois a modificação

[...] facilita ao profissional abordar diversos problemas como atividade sexual precoce, pressáo de grupo, uso de drogas, prevençáo de acidentes, escolha profissional [...] (MEIRELLES; RUZANY, 2008, p. 38),

temas que são tão pesados, mas que, ao fazer esse ajustamento de linguagem, são discutidos de forma leve e clara, pois fazem parte do contexto da adolescência e é de suma importância serem abordados.

\section{Objetivo geral}

Analisar a eficácia das atividades grupais utilizadas na Terapia Ocupacional como estratégias utilizadas no aquecimento de rodas de terapia comunitária em um grupo de adolescentes.

\subsection{Objetivos específicos}

- Levantar estratégias para o aquecimento utilizadas como recurso para início da roda;

- Investigar os comportamentos mais frequentes apresentados no desenvolvimento das atividades;

- Correlacionar as estratégias utilizadas no aquecimento/acolhimento com os temas discutidos na roda;

- Contribuir com publicações de artigos referentes ao assunto. 


\section{Metodologia}

\subsection{Local}

A pesquisa foi realizada na Casa da Acolhida Marista do município de Uberaba, no estado de Minas Gerais. Essa instituição foi selecionada por realizar semanalmente roda de terapia comunitária, além de ser uma instituição social que visa o apoio à infância, juventude e cidadania, com a finalidade de resgatar e acolher crianças e adolescentes em situação de vulnerabilidade proporcionando a eles o fortalecimento da autoestima, pessoal e social, assim como a facilitação à inclusão social (MARISTA, 2010).

\subsection{Participantes}

Fizeram parte desta pesquisa 11 adolescentes que se encontram em situação de vulnerabilidade por residirem em regióes de periferia da cidade de Uberaba e que estão expostos constantemente à violência e ao envolvimento com drogas dentro ou fora do ambiente familiar, dentre eles 8 do gênero masculino e 3 do gênero feminino com idade entre 12 e 14 anos.

\subsection{Seleção dos participantes}

Os critérios de inclusão estabelecidos para a participação dos sujeitos na pesquisa foram adolescentes com idade entre 12 e 14 anos, autorizado pelos responsáveis, o adolescente aceitar participar da pesquisa após a apresentaçáo da proposta ao grupo e ser integrante das rodas de terapia comunitária. $\mathrm{O}$ primeiro contato com os pais foi através de reuniáo para a apresentaçáo da pesquisa e do Termo de Consentimento Livre e Esclarecido, que traz os objetivos, o destino do material coletado e informação referente à integridade dos participantes.

\subsection{Instrumento}

Para o desenvolvimento do trabalho, foi realizado um levantamento em bibliografias de estratégias/ dinâmicas que abordem as categorias: competição, cooperação e autoconhecimento/autoestima, com a duração máxima de 30 minutos e mínima de 15 minutos, sendo selecionadas 12 estratégias para aplicação e destinados igualmente a cada categoria 4 encontros. Dentre as dinâmicas que abordavam esses eixos temáticos em livros pesquisados, foram selecionadas 12 dinâmicas que contemplavam o perfil do grupo. Já a escolha das categorias abordadas foi elencada, por se tratar de temas que fazem parte do universo dos adolescentes e que devem ser trabalhados para a formação da concepção de um adulto resiliente.

A aplicação das estratégias foi realizada em 12 encontros no momento do acolhimento/aquecimento antes do início das rodas de TC, que têm como coordenadores dois terapeutas comunitários, sendo um deles terapeuta ocupacional. Para a coleta de dados, foram utilizados os recursos da filmagem, fotos e registro manuscrito a fim de auxiliar na discussão dos resultados.

\subsection{Procedimento}

Primeiramente, o projeto foi encaminhado ao Comitê de Ética em Pesquisa em Seres Humanos da Universidade de Uberaba e após o parecer de aprovação (CAAE - 0034.0.227.000-10) deu início à coleta de dados através do levantamento e aplicação das estratégias divididas em 3 categorias (competição, cooperação e autoconhecimento/autoestima). Em seguida, foi realizada a análise das estratégias e o comportamento apresentado pelos adolescentes no momento do aquecimento e da roda e a correlação das estratégias com os temas discutidos nas rodas de TC.

\subsubsection{Procedimento de análise de dados}

A análise dos dados foi realizada a partir da abordagem qualitativa descritiva com a construção de quadros para apresentar os dados obtidos durante a pesquisa. O tipo de estudo descritivo tem por objetivo, segundo Gil (1991), apresentar a descrição das características de determinada população e as relações entre suas variáveis. O Quadro 1 refere-se ao levantamento em bibliografias das estratégias encontradas em cada categoria.

Para observação dos dados de cada categoria, foram elaborados quadros subdivididos em 6 colunas que constam: estratégia abordada no aquecimento, tema na roda, gênero, número de participantes, idade, comportamento desencadeado (no aquecimento e na roda), seguido de suas respectivas análises.

\section{Resultados e discussão}

Os primeiros dados apresentados correspondem ao Quadro 1, que apresenta o levantamento em bibliografias referente ao número de dinâmicas/ 
estratégias encontradas de acordo com as categorias propostas, totalizando 33 dinâmicas, divididas em 3 categorias: 1 - competição; 2 - cooperação e 3 - autoconhecimento/autoestima. Para a categoria 1 foram selecionadas inicialmente 6 dinâmicas/ estratégias; para a categoria $2-13$ dinâmicas/ estratégias e para a categoria 3 - 14 dinâmicas/ estratégias de acordo com o quadro.

Do total de 33 dinâmicas, foram selecionadas 12 estratégias de acordo com as características obtidas do grupo e pela flexibilidade das dinâmicas na substituição dos recursos utilizados por materiais de baixo custo, 5 sofreram adaptaçóes do modelo original por causa do material e de acordo com as características do grupo. Entretanto, essas adaptaçôes não influenciaram no objetivo e no resultado do trabalho. Os dados e resultados da pesquisa podem ser observados nos quadros abaixo, seguidos da análise referente à aplicação das estratégias utilizadas.

O Quadro 2 apresenta as estratégias utilizadas no aquecimento antes do início da roda de TC, a relação dessas estratégias com o tema discutido, a caracterização do gênero presente e o comportamento

Quadro 1. Dinâmicas/estratégias encontradas.

\begin{tabular}{|c|c|}
\hline Categorias & Dinâmicas \\
\hline Categoria 1 & $\begin{array}{l}\text { Corrida de carros; A forca; A ponte; Autógrafos II; Briga de galo; Concordo... discordo; } \\
\text { Corrida dos sacos; Estourando balões; } \\
\text { Ganhando no grito; O dia da fama; Pernas amarradas; } \\
\text { Pisando no papelão; Terra, céu e mar; }\end{array}$ \\
\hline Categoria 2 & $\begin{array}{l}\text { A invasão dos caranguejos gigantes; A travessia da ponte estreita; } \\
\text { Caça ao tesouro; Escravos de Jó; Jogo dos quadrados; Os náufragos; }\end{array}$ \\
\hline Categoria 3 & $\begin{array}{l}\text { A escolha; Abrindo janelas; Águia pequena; As cores dos sentimentos; Caminhando e } \\
\text { cantando; Carências \& competências; } \\
\text { Dar e receber afeição; Eu sou eu; Exercício (dentro) e (fora); Gravuras; O mapa do } \\
\text { comportamento; O melhor de mim; O paiol de emoções; Olho no olho; }\end{array}$ \\
\hline Total & 33 dinâmicas \\
\hline
\end{tabular}

Fonte: pesquisadores.

Quadro 2. Estratégias utilizadas na categoria competição.

\begin{tabular}{|c|c|c|c|c|c|c|}
\hline \multirow[t]{2}{*}{ Estratégia } & \multirow{2}{*}{$\begin{array}{l}\text { Tema da } \\
\text { roda }\end{array}$} & \multicolumn{4}{|c|}{ Caracterização do gênero } & \multirow{2}{*}{$\begin{array}{l}\text { Comportamento } \\
\text { No aquecimento } \\
\text { Na roda }\end{array}$} \\
\hline & & $\mathbf{M}$ & $\mathbf{F}$ & $\begin{array}{c}\text { N. de } \\
\text { participantes }\end{array}$ & Idade & \\
\hline $\begin{array}{l}\text { 1. O dia de fama } \\
\text { Escrever o nome no centro da folha, } \\
\text { ao sinal do coordenador, dar e receber } \\
\text { autógrafos, vence o que conseguir o } \\
\text { maior número de autógrafos. }\end{array}$ & Inveja & 3 & 3 & $\begin{array}{l}1 \\
3 \\
2\end{array}$ & $\begin{array}{l}12 \text { anos } \\
13 \text { anos } \\
14 \text { anos }\end{array}$ & $\begin{array}{c}\text { Disputa } \\
\text { Tranquilidade }\end{array}$ \\
\hline $\begin{array}{l}\text { 2. Estourando balões } \\
\text { O participante com } 2 \text { balões amarrado } \\
\text { à cintura ao sinal do coordenador terá } \\
\text { que cuidar do seu balão e estourar } \\
\text { o do colega, vence permanecer com } \\
\text { pelo menos } 1 \text { dos balões. }\end{array}$ & Pedofilia & 5 & 3 & $\begin{array}{l}1 \\
5 \\
2\end{array}$ & $\begin{array}{l}12 \text { anos } \\
13 \text { anos } \\
14 \text { anos }\end{array}$ & $\begin{array}{l}\text { Violência } \\
\text { Agitação }\end{array}$ \\
\hline $\begin{array}{l}\text { 3. Pernas amarradas } \\
\text { O participante terá } 2 \text { fitas, uma para } \\
\text { amarrar nas pernas e a outra nas } \\
\text { mãos, ao sinal do coordenador vence } \\
\text { aquele que desamarrar primeiro. }\end{array}$ & $\begin{array}{l}\text { Máscaras } \\
\text { para ser } \\
\text { aceito na } \\
\text { sociedade }\end{array}$ & 3 & 2 & $\begin{array}{l}1 \\
3 \\
1\end{array}$ & $\begin{array}{l}12 \text { anos } \\
13 \text { anos } \\
14 \text { anos }\end{array}$ & $\begin{array}{l}\text { Pacífico } \\
\text { Reflexão }\end{array}$ \\
\hline $\begin{array}{l}\text { 4. Pisando no papelão } \\
\text { O participante terá que percorrer um } \\
\text { espaço delimitado pisando em pés } \\
\text { de papelão, vence aquele que fizer o } \\
\text { menor tempo. }\end{array}$ & Poder & 4 & 3 & $\begin{array}{l}4 \\
3\end{array}$ & $\begin{array}{l}13 \text { anos } \\
14 \text { anos }\end{array}$ & $\begin{array}{l}\text { 1. Disputa } \\
\text { 2. Identificação }\end{array}$ \\
\hline
\end{tabular}

Fonte: pesquisadores. 
apresentado pelos adolescentes durante o aquecimento e na roda.

Ao observar o quadro apresentado podemos identificar que durante o aquecimento 1 permaneceu a competitividade entre os adolescentes que estavam presentes, 3 do gênero masculino e 3 do gênero feminino, ao disputar entre si o número de autógrafos. Entretanto, esteve presente o espírito de equipe e colaboração mútua entre os integrantes do grupo ao receber e oferecer autógrafos uns dos outros durante a atividade, pois à medida que iam recebendo os autógrafos estes também ofereciam, colaborando com os demais colegas. Já no momento da roda o grupo debateu o tema escolhido, de forma tranquila em que foi discutido o ponto de vista que cada um tem a respeito da inveja e os motivos que os levam a sentir inveja. O principal motivo apontado pelo grupo foi "ter inveja do amigo", porém durante o debate foi apontado o lado positivo da inveja como forma de aproximação e admiração daquele por quem se manifesta o sentimento.

O tema proposto sugerido por um adolescente (13 anos) pode ter sido influenciado pela atividade aplicada, uma vez que esta foi realizada através de uma disputa e o adolescente que sugeriu o tema não foi o que venceu. Segundo Maia (2008), na busca da sua identidade, a todo momento o adolescente sente uma necessidade constante de confrontação com os outros, procurando novos modelos e novas identificações.

No aquecimento 2 , os participantes -5 do gênero masculino e 3 do gênero feminino - realizaram a atividade com violência ao estourar as bexigas de maneira desordenada, provocando tumulto e agressóes para com os colegas do grupo e principalmente contra as meninas. Já no momento da roda o grupo apresentou-se agitado e, ao discutir o tema da roda indicado por um adolescente (13 anos), muitas dúvidas foram elencadas e na fala dos adolescentes a violência - nesse contexto a vítima de violência sexual na infância - foi apontada como um dos motivos que levam uma pessoa a cometer a pedofilia. Trouxeram em suas falas o fato de a violência sexual ter início dentro da própria família e, mesmo tendo conhecimento do assunto, muitos relataram que não saberiam identificar um possível agressor e demonstraram insegurança ao falar sobre o tema.

O tema foi pertinente ao aquecimento aplicado, pois foram destacadas as regras burladas pelo grupo durante a atividade que manteve característica violenta, assim como o tema eleito na roda representa uma das faces da violência. Para Maia (2008), nos adolescentes as emoçóes brotam de tal forma que geram grande instabilidade, incertezas, provocando por vezes, como resposta, uma violência exacerbada, o que leva o adolescente a carregar o estigma de violento.

No aquecimento 3, o grupo contou com 3 adolescentes do gênero masculino e 2 do gênero feminino e o comportamento permaneceu de forma pacífica, ao realizar com tranquilidade a estratégia oferecida. O número reduzido de adolescentes presentes nesse encontro influenciou de forma direta no desenvolvimento do grupo.

$\mathrm{Na}$ roda, o tema escolhido foi indicado por um adolescente (13 anos) e, com poucos adolescente no grupo, o tema gerou debate e reflexóes ao discutir a aceitação em um grupo de nível socioeconômico elevado, para tal os adolescentes apontam a necessidade de "usar máscaras para ser aceito em grupo e ter amigos", ou seja, idealizar ter um nível socioeconômico e ser uma pessoa diferente daquela que condiz com sua realidade.

No contexto de grupo, o adolescente sente a necessidade de se autoafirmar, uma vez que o grupo representa seu contexto social. Por isso, a necessidade de ser aceito pelo grupo e adquirir cada vez mais sua independência, pois é o espaço das trocas de experiências e onde eles falam e fazem coisas comuns, o que náo acontece no contexto familiar.

Durante a roda, ao serem feitos questionamentos sobre o assunto, o grupo tem a consciência de que se devem autovalorizar as qualidades e aceitar-se como é. O medo de serem julgados pelos demais colegas ao não ter condiçôes financeiras suficientes para adquirir produtos da moda os leva à idealizaçâo de outra identidade pessoal.

Todo o contexto foi discutido de maneira tranquila em que o grupo fez suas colocaçóes acerca do tema abordado admitindo suas falhas e assumindo suas fraquezas.

De acordo com Maia (2008, p. 24):

[...] é necessário que o adolescente se identifique primeiro com o grupo para posteriormente definir qual é o seu papel na família e na sociedade. Na primeira fase da adolescência, é importante para o adolescente sentir-se integrado num grupo, em que tem de obedecer às normas existentes nesse grupo, o que leva a uma identificaçáo com os restantes membros, porque usam o mesmo penteado, vestem roupas iguais, ouvem a mesma música e falam a mesma linguagem. Este sentido de autoafirmação poderá levá-lo à não conformidade com a geração dos seus pais.

No aquecimento 4 , estavam presentes 4 adolescentes do gênero masculino e 3 do gênero 
feminino. Essa estratégia favoreceu o clima de disputa entre os adolescentes, talvez tenha sido a atividade que melhor despertou o sentimento de competição entre o grupo. Pelo acontecimento, os participantes eliminados na primeira rodada se organizaram em torcidas, porém vale ressaltar que a atividade foi realizada sem maiores transtornos, talvez pelo fato de não necessitar do contato físico com o concorrente.

Durante a roda a discussão inicial entre a relação da capacidade e habilidade independente da estatura física apresentou relação direta com o aquecimento proposto, pois o vencedor da estratégia foi o adolescente com a menor estatura do grupo, o que alimentou uma segunda discussão proposta ao grupo na escolha de um personagem da ficção de desenhos animados e/ou seriados seguido da justificativa, surgindo assim o tema escolhido da roda.

Nessa relação, a característica dos personagens que sobressaiu às demais foi o poder, identificado com as características do grupo no relato de uma das adolescentes que diz "no grupo um quer exercer mais poder do que o outro sobre os demais". O debate girou em torno da identificação do sentimento de poder de cada um e o aquecimento contribuiu para essa discussão uma vez que os adolescentes que exercem o poder sobre o grupo foram eliminados na primeira fase da competição.

Nessa primeira categoria, os temas indicados para discussão na roda foram todos de jovens do sexo masculino com idade de 13 anos - um dos motivos refere-se ao maior número de adolescentes do gênero masculino em relaçáo ao feminino presente no grupo. Todos os sentimentos e alteraçóes do grupo frente aos questionamentos abordados nos temas $\mathrm{da}$ roda correspondem às alteraçôes emocionais que o adolescente vive e a busca constante de sua identidade pessoal para formar suas opinióes e construir suas concepçóes. Maia (2008) aponta que as alteraçóes emocionais oriundas das modificaçôes psicológicas no desenvolvimento do adolescente despertam desejos e sentimentos até então desconhecidos, que dão ao jovem a impressão de que é uma pessoa diferente.

O Quadro 3, refere-se à categoria cooperação em que foi analisado o comportamento dos adolescentes em grupo e o desenvolvimento dos mesmos ao

Quadro 3. Estratégias utilizadas na categoria cooperação.

\begin{tabular}{|c|c|c|c|c|c|c|}
\hline \multirow[t]{2}{*}{ Estratégia } & \multirow{2}{*}{$\begin{array}{l}\text { Tema da } \\
\text { roda }\end{array}$} & \multicolumn{4}{|c|}{ Caracterização do gênero } & \multirow{2}{*}{$\begin{array}{c}\text { Comportamento } \\
\text { no aquecimento / } \\
\text { na roda }\end{array}$} \\
\hline & & $\mathbf{M}$ & $\mathbf{F}$ & N. de participantes & Idade & \\
\hline $\begin{array}{l}\text { 1. A travessia da ponte estreita } \\
\text { Divide-se em } 2 \text { equipes, uma } \\
\text { em cada extremidade da } \\
\text { ponte, ao sinal do coordenador } \\
\text { as duas terão que passar } \\
\text { simultaneamente pela ponte } \\
\text { sem cair }\end{array}$ & $\begin{array}{l}\text { Raiva dos } \\
\text { colegas }\end{array}$ & 4 & 0 & $\begin{array}{l}1 \\
4 \\
2\end{array}$ & $\begin{array}{l}12 \text { anos } \\
13 \text { anos } \\
14 \text { anos }\end{array}$ & $\begin{array}{l}\text { Repressor } \\
\text { Agitação }\end{array}$ \\
\hline $\begin{array}{l}\text { 2. Náufrago } \\
\text { Formam-se } 2 \text { equipe, com: } \\
\text { integrantes cego, sem braço e } \\
\text { mudo, conta-se uma história } \\
\text { envolvendo uma ilha deserta e } \\
\text { a necessidade de construir um } \\
\text { balde, quem concluir será a } \\
\text { vencedora. }\end{array}$ & Obesidade & 4 & 3 & $\begin{array}{l}1 \\
4 \\
2\end{array}$ & $\begin{array}{l}12 \text { anos } \\
13 \text { anos } \\
14 \text { anos }\end{array}$ & $\begin{array}{c}\text { 1. União } \\
\text { 2. Sociabilidade }\end{array}$ \\
\hline $\begin{array}{l}\text { 3. Jogo dos quadrados } \\
\text { Formam-se } 2 \text { equipes, cada } \\
\text { uma receberá um pacote com } \\
17 \text { peças embaralhadas, o grupo } \\
\text { terá que montar um quadrado, } \\
\text { sem haver comunicação verbal. }\end{array}$ & $\begin{array}{l}\text { Trabalho } \\
\text { em grupo }\end{array}$ & 4 & 2 & $\begin{array}{l}1 \\
3 \\
2\end{array}$ & $\begin{array}{l}12 \text { anos } \\
13 \text { anos } \\
14 \text { anos }\end{array}$ & $\begin{array}{l}\text { 1. Interação } \\
\text { 2. Agitação }\end{array}$ \\
\hline $\begin{array}{l}\text { 4. O tesouro do pirata } \\
\text { O grupo terá que encontrar } 5 \\
\text { cartas perdidas e realizar o que } \\
\text { está solicitado seguindo a ordem } \\
\text { numérica até chegar na arca do } \\
\text { tesouro. }\end{array}$ & Raiva & 6 & 2 & $\begin{array}{l}1 \\
5 \\
2\end{array}$ & $\begin{array}{l}12 \text { anos } \\
13 \text { anos } \\
14 \text { anos }\end{array}$ & $\begin{array}{l}\text { 1. Sociabilidade } \\
\text { 2. Sociabilidade }\end{array}$ \\
\hline
\end{tabular}

Fonte: pesquisadores. 
trabalhar em equipe, além de apresentar as estratégias utilizadas no aquecimento antes do início da roda de TC, a relação dessas estratégias com o tema da roda e a caracterização do gênero presente na roda.

Durante o aquecimento 1 , estavam presentes no grupo 3 adolescentes do gênero feminino e 4 do gênero masculino. Uma das equipes repreendeu a outra ao burlar as regras impostas, ao usar a força física e resistência para eliminar o concorrente da competição; apesar do comportamento inadequado frente às regras da dinâmica, o trabalho em equipe foi realizado.

$\mathrm{Na}$ roda, o tema foi indicado por um adolescente (13 anos) e desencadeou a discussão sobre as falsas informaçóes comentadas pelos colegas e como a melhor forma de resolver possíveis contestaçóes de informações não verídicas. Apontada pelos adolescentes, a sinceridade foi eleita como solução, durante o debate o grupo permaneceu agitado, com todos expondo seus questionamentos e opinióes ao mesmo tempo, não respeitando também as regras da roda.

$\mathrm{O}$ aquecimento favoreceu de forma indireta na escolha do tema, pois a discussão iniciou devido a acusaçôes feitas pela equipe repreendida durante o aquecimento, o que pode ter influenciado na sugestáo do tema para votação. A ofensiva geral do adolescente ao infringir as regras, de acordo com Maia (2008), é uma forma de ousar de maneira desordenada mais ou menos incoerente, pois necessita de atenção e ajuda para organizar seus pensamentos e lutar por sua identidade.

Durante o aquecimento 2, estavam presentes 4 adolescentes do gênero masculino e 3 do gênero feminino, as duas equipes se envolveram na atividade e empenharam-se na realização do trabalho proposto. Uma das equipes não apresentou interação entre seus membros, perdeu tempo observando os concorrentes que conseguiram realizar a prova com êxito, porém vale ressaltar que ambas as equipes apresentaram-se atentas e unidas durante a execução da atividade de aquecimento.

$\mathrm{Na}$ roda, o tema escolhido foi a obesidade, sugerido por um adolescente (13 anos), tema este desencadeado através do aquecimento, pois foi atribuído a esse adolescente a derrota de sua equipe. Por ser sempre criticado pelos demais colegas do ciclo de amigos e estar acima do peso, trouxe para a roda a discussão sobre o incômodo das críticas, outros adolescentes também relataram ter passado por situações parecidas de críticas e exclusão, por isso o grupo interagiu no contexto proposto da discussáo, contribuindo com suas experiências e empatia.
No aquecimento 3 , os adolescentes presentes foram 4 do gênero masculino e 2 do sexo feminino, as duas equipes interagiram e trabalharam empenhadas na busca do resultado final da atividade, sendo que uma delas apresentou maior interação entre seus membros o que contribuiu para o fato de conseguir finalizar a atividade em pouco tempo e com tranquilidade.

Já durante a roda, o tema escolhido foi sugerido por um adolescente (13 anos) e teve influência direta com o aquecimento, pois a equipe que não conseguiu realizar a atividade trouxe para a roda o questionamento da realização de trabalhos em grupo e da interaçáo de seus membros para obter as conquistas. Durante a discussão acerca do tema, foi percebida agitação motora e verbal em todos os participantes da roda, em evidência o grupo que perdeu a disputa.

No aquecimento 4, participaram da estratégia 6 adolescentes do gênero masculino e 2 do gênero feminino, o grupo como um todo trabalhou integrado na execução das provas, possibilitando alcançar os objetivos propostos, uma vez que houve colaboração ao socializarem suas habilidades e realizar o que foi sugerido nas cartas do pirata.

O tema escolhido pela roda novamente foi proposto por um adolescente (13 anos), tema já abordado nessa categoria, porém o enfoque da raiva foi no contexto de ajudar e não ser reconhecido. No relato dos adolescentes, essa ajuda vem acompanhada por uma recompensa e quando esta não acontece surge a raiva, todo o grupo contribuiu com suas experiências. Ao assumir suas identificaçóes com o tema, alguns adolescentes relataram ajudar sem interesse, porém a grande maioria assumiu o interesse na ajuda.

O aquecimento favoreceu a discussáo do tema escolhido e nos depoimentos dos mesmos, uma vez que a atividade proposta instigou todo o grupo a se ajudar para conquista da recompensa.

A participação de adolescentes do gênero masculino nessa categoria foi relevante, uma vez que todos os temas sugeridos e discutidos durante as rodas também foram indicados por adolescentes do gênero masculino na faixa etária dos 13 anos de idade. O comportamento apresentado pelos adolescentes nos dois momentos do encontro (aquecimento e a roda) refletem na reorganizaçáo pessoal e social que se inicia na adolescência, e geralmente para se chegar a uma reflexão sobre determinado tema é necessário passar por momentos de contestações, rebeldia, inquietações e até mesmo transgressões a fim de atingir o objetivo principal. 
O Quadro 4 refere-se à categoria autoconhecimento/autoestima, uma vez que a supervalorização da autoestima entre adolescentes do grupo trabalhado existe, porém quanto ao autoconhecimento os adolescentes sentem-se inseguros ao falar de si. O quadro que segue apresenta as estratégias utilizadas no aquecimento antes do início da roda de TC, a relação dessas estratégias com o tema da roda, caracterização do gênero presente e o comportamento apresentado durante o aquecimento e na roda.

No aquecimento 1, participaram 7 adolescentes do gênero masculino e 3 do gênero feminino, o grupo permaneceu desatento todo o tempo, sendo necessário repetir as regras da dinâmica por várias vezes. Após o término da primeira etapa, o comportamento predominante foi de total desatenção aliada ao desinteresse no momento do fechamento da atividade, fato que resultou na suspensão das apresentaçóes das carências e competências do grupo. Após análise das carências e competências, os dados relevantes encontrados foram: carências - chato, mentiroso, preguiçoso e competências - amigo, bonito, sincero. Nesse encontro, não foi realizada a roda de TC, uma vez que os coordenadores responsáveis pela roda não estavam presentes, não sendo possível, portanto, analisar o comportamento e a influência do aquecimento aplicado durante o desenvolvimento da roda.

No aquecimento 2, a atividade proposta foi desenvolvida com 6 adolescentes somente do gênero masculino. $\mathrm{O}$ desinteresse foi o ponto alto desse encontro. $\mathrm{O}$ grupo não demonstrou em nenhum momento atenção ao realizar a atividade e alguns dos adolescentes se recusaram a participar. Novamente o grupo não respeitou as regras para a finalização da atividade, posteriormente ao analisar as características relevantes dos dados colhidos: mentiroso, legal,

Quadro 4. Estratégias utilizadas na categoria autoconhecimento/autoestima.

\begin{tabular}{|c|c|c|c|c|c|c|}
\hline \multirow[t]{2}{*}{ Estratégia } & \multirow{2}{*}{$\begin{array}{l}\text { Tema da } \\
\text { roda }\end{array}$} & \multicolumn{4}{|c|}{ Caracterização do gênero } & \multirow{2}{*}{$\begin{array}{c}\text { Comportamento } \\
\text { no aquecimento/ } \\
\text { na roda }\end{array}$} \\
\hline & & $\mathbf{M}$ & $\mathbf{F}$ & N. de participantes & Idade & \\
\hline $\begin{array}{l}\text { 1. Carência e competência } \\
\text { Em uma folha branca dobrada } \\
\text { ao meio, deverão ser desenhados } \\
\text { a mão direita e a esquerda, em } \\
\text { seguida deve escrever na mão } \\
\text { direita } 5 \text { competências que possui } \\
\text { e na esquerda } 5 \text { carências. }\end{array}$ & & 7 & 3 & $\begin{array}{l}1 \\
6 \\
3\end{array}$ & $\begin{array}{l}12 \text { anos } \\
13 \text { anos } \\
14 \text { anos }\end{array}$ & Desatenção \\
\hline $\begin{array}{l}\text { 2. Eu sou... } \\
\text { Em uma folha escreve-se na } \\
\text { margem superior "Eu sou" e } \\
\text { ao sinal do coordenador todos } \\
\text { deverão escrever à vontade no } \\
\text { tempo, ao final cada participante } \\
\text { deverá se apresentar. }\end{array}$ & $\begin{array}{l}\text { Guerra do } \\
\text { tráfico }\end{array}$ & 6 & 0 & $\begin{array}{l}4 \\
2\end{array}$ & $\begin{array}{l}13 \text { anos } \\
14 \text { anos }\end{array}$ & $\begin{array}{c}\text { Desinteresse } \\
\text { Revolta }\end{array}$ \\
\hline $\begin{array}{l}\text { 3. As cores dos sentimentos } \\
\text { Em circulo cada participante deve } \\
\text { fechar os olhos e buscar associar } \\
\text { o seu sentimento a uma cor e } \\
\text { pegar no centro da roda o cartão } \\
\text { colorido referente à cor do seu } \\
\text { sentimento, ao final devem-se } \\
\text { encontrar uma palavra e uma cor } \\
\text { que caracterize o grupo. }\end{array}$ & Violência & 3 & 0 & $\begin{array}{l}2 \\
1\end{array}$ & $\begin{array}{l}13 \text { anos } \\
14 \text { anos }\end{array}$ & $\begin{array}{l}\text { Sociabilidade } \\
\text { Sociabilidade }\end{array}$ \\
\hline $\begin{array}{l}\text { 4. O melhor de mim } \\
\text { Disponibilizam-se uma folha e } \\
\text { diversos materiais para construção } \\
\text { de um cartaz com o melhor de si, } \\
\text { ao final do tempo estipulado cada } \\
\text { um deverá apresentar o seu cartaz } \\
\text { e oferecer o melhor de si a um dos } \\
\text { participantes. }\end{array}$ & & 6 & 2 & $\begin{array}{l}2 \\
3 \\
3\end{array}$ & $\begin{array}{l}12 \text { anos } \\
13 \text { anos } \\
14 \text { anos }\end{array}$ & Desinteresse \\
\hline
\end{tabular}

Fonte: pesquisadores. 
bagunceiro e brigão foram as características mais citadas entre os participantes.

Durante a roda, o tema escolhido foi indicado por um adolescente (13 anos) devido aos acontecimentos recentes divulgados na mídia envolvendo o combate ao tráfico de drogas. O grupo manifestou apoio aos traficantes ao verbalizar de forma agressiva suas opinióes em defesa dos mesmos, pelo fato dos homens do tráfico exercerem o poder sobre uma comunidade e até mesmo sobre a polícia. Um dos adolescentes traz em sua fala que "os adolescentes de hoje gostam da violência e não gostam de estudar". Durante a roda, surgiram manifestaçôes contrárias à colocação desse adolescente e relatos de que a violência não é a melhor solução para resolver os problemas. Diante do exposto, o aquecimento náo contribuiu com a indicação e escolha do tema, prevalecendo a influência que a mídia exerce sobre os adolescentes.

Durante a aplicação do aquecimento 3 , o grupo contou com poucos integrantes, apenas 3 do gênero masculino. Esse fato enriqueceu a discussão, pois os adolescentes participantes apresentaram suas pontuaçóes e justificativas durante o aquecimento de forma coerente e pacífica. Quanto às cores e sentimentos correlacionados, estes foram: laranja - páscoa; branco - felicidade e paz; vermelho - amor; prata - natal, diante das sugestóes apresentadas, foi proposta uma votação para caracterizar o grupo. A cor eleita foi o verde que segundo o grupo representa uma sociedade sem desigualdade.

Diante do tema escolhido indicado por um adolescente (13 anos) o grupo manteve os mesmos comportamentos apresentados no momento do aquecimento, partilhando suas experiências e contribuindo para o desenvolvimento da roda, o tema votado - a violência associou-se ao questionamento de fatores que levam uma pessoa a se envolver com tráfico de drogas.

O grupo apontou como principal motivo para o envolvimento com as drogas a busca pelo poder seguida do dinheiro fácil, influência dos amigos e a falta de diálogo com os pais. Alguns adolescentes trazem em seus relatos ter vivenciado algumas dessas situaçóes. O grupo também cita alguns elementos essenciais para não se deixar influenciar pela violência e o mundo das drogas, entre eles: carinho, amor a si e resiliência. Diante do exposto, o aquecimento contribuiu de forma indireta na discussão do tema ao elencar os sentimentos como elementos fundamentais para evitar a violência e a vulnerabilidade de lidar com o mundo das drogas, e fortalecer a construção da identidade pessoal.

No aquecimento 4, estavam presentes 6 adolescentes do gênero masculino e 2 do gênero feminino, durante o aquecimento o grupo apresentou desinteresse na realização da atividade, não respeitando regras e limites estabelecidos. $\mathrm{O}$ clima de desatençáo esteve presente durante todo o aquecimento, impossibilitando o fechamento desta e das demais atividades propostas durante os 12 encontros da realizaçáo da pesquisa.

Nesse encontro, não foi realizada a roda de TC, uma vez que os coordenadores responsáveis pela roda não estavam presentes, não sendo possível analisar a eficácia do aquecimento aplicado. Novamente nessa categoria, assim como na categoria 2 , a prevalência de adolescentes do gênero masculino foi maior que do gênero feminino. Quanto ao comportamento apresentado durante os aquecimentos propostos, o desinteresse pelas estratégias aplicadas nessa categoria foi evidente ao comparar com a categoria 1 e 2 .

O comportamento apresentado durante toda a categoria 3 demonstra que os adolescentes apresentaram a dificuldade que é típica dessa fase em se expor, seja pelo medo do ridículo para com os demais colegas ou por desconfiança entre o grupo, como uma forma de defesa criada pelas situaçóes vivenciadas.

Analisando o comportamento apresentado nessa categoria por outra vertente, Maia (2008) esclarece que as alterações corporais podem despertar sentimentos de vergonha, timidez, pudor e até ansiedade no adolescente em todo o contexto social (família, escola, lazer), outro fator é a chamada "crise da adolescência”, que muitos autores a caracterizam pelas confusóes, contradiçóes e ambivalências que os jovens vivem, assim como as constantes oscilaçóes entre a independência por meio da necessidade de autonomia e a dependência através das manifestaçóes de proteção.

Nos 12 encontros estabelecidos, o número de adolescentes na roda de terapia comunitária oscilou variando entre 3 e 10 adolescentes a cada encontro, de acordo com os quadros apresentados. Essa oscilação não alterou os resultados deste estudo, uma vez que foi possível aplicar todas as estratégias/dinâmicas selecionadas.

Durante a pesquisa, os comportamentos mais frequentes apresentados no aquecimento foram agitação, disputa e desinteresse, já durante as rodas de TC o comportamento predominante foi o de sociabilidade em que todos partilharam de suas experiências e inseguranças, a agitação também foi identificada como comportamento relevante presente em muitas rodas, comportamentos correspondentes ao período da adolescência.

Todos os temas escolhidos através de votação na roda foram indicados por adolescentes do gênero masculino com 13 anos idade - fase considerada como o ponto alto da pré-adolescência, em que o 
adolescente está se adaptando às transformaçóes físicas e na busca de resposta quanto ao mundo e seus fatos e sobre o seu próprio existir, sua identidade. Entretanto, foi possível identificar a relação direta entre o aquecimento e o tema discutido na roda, exceto em algumas estratégias em que essa relação foi estabelecida de forma indireta.

\section{Considerações finais}

De acordo com o exposto, considera-se que este trabalho atingiu os objetivos propostos, pois foi possível identificar a eficácia das dinâmicas utilizadas no aquecimento, através do comportamento menos resistente e mais descontraído dos adolescentes durante o momento da roda de TC, assim como, a contribuição com suas opiniốes e experiências pessoais, o que comprova os ganhos ao fazer uso desse tipo de abordagem com a populaçáo em questão.

Por não demandarem da utilização de materiais de alto custo, as estratégias escolhidas são dinâmicas simples que promoveram a interação e interesse do grupo durante sua aplicação. E em vários momentos desencadearam a discussão de temas abordados na roda, favorecendo a sociabilidade entre seus participantes, entretanto, por se tratar de um estudo focal, não significa que todas as estratégias utilizadas irão emergir nas temáticas encontradas neste trabalho.

Nesse contexto, o terapeuta ocupacional, ao possuir grande conhecimento na atuação em grupo, favorece o desenvolvimento da roda, uma vez que possui domínio sobre o assunto e faz uso das dinâmicas/estratégias como recurso terapêutico na sua intervenção. Por isso, o terapeuta ocupacional é um dos profissionais de maior competência para somar seus conhecimentos com a terapia comunitária que favorecerá uma roda rica em conteúdo e desenvolvimento.

Diante da complexidade de novas identificaçôes e experimentaçôes que constituem o universo do adolescente, espera-se que esta proposta de trabalho seja vivenciada por outros profissionais, principalmente pelos terapeutas ocupacionais, em diferentes locais e períodos no decorrer do ano, para que estes agreguem informaçóes, conhecimento e novas experiências acerca do tema abordado e do instrumento de intervenção utilizado.

\section{Referências}

ANDRADE, E. D. C. Compartilhar é o melhor remédio. [s.l.]: Abratecom, 2007. Disponível em: <http://www. abratecom.org.br/publicacoes/teses/pdf/sumuario_comtcc. pdf $>$. Acesso em: 12 abr. 2011.

ASSIS, S. G. et al. Resiliência na Adolescência: Refletindo com educadores sobre superação de dificuldades. Rio de Janeiro: Fiocruz, Ensp/claves, CNPq, 2008.

BALLARIN, M. L. G. S. Abordagens Grupais. In: CAVALCANTI, A.; GALVÃO, C. Terapia Ocupacional: fundamentação \& prática. Rio de Janeiro: Guanabara Koogan, 2007. cap. 7, p. 38-43.

BARRETO, A. P. Terapia Comunitária: passo a passo. 3. ed. Fortaleza: Gráfica LCR, 2008.

BRASIL. Ministério da Saúde. Secretaria de Atenção À Saúde. Área de Saúde do Adolescente e do Marco legal: saúde, um direito de adolescentes. Brasília: Ministério da Saúde, 2005.

BRASIL. Presidência da República. Lei Federal 8069/90: Estatuto da Criança e do Adolescente. Brasília:CMDCA, 1990.

GIL, A. C. Como elaborar projetos de pesquisa. São Paulo: Atlas, 1991.

MAIA, A. C. S. B. Saúde e Adolescência: Hábitos e Comportamentos dos adolescentes que frequentam clínica privada no concelho do Barreiro. 2008. 268 f. Dissertaçáo (Mestrado Ciências da Educação)-Universidade Técnica de Lisboa, Lisboa, 2008. Disponível em: <http://www. repository.utl.pt/bitstream/10400.5/1511/1/Tese.pdf>. Acesso em: 28 mar. 2011.

MARISTA. Diocesano. Casa da Acolhida Marista de Uberaba. Disponível em: <http://marista.edu. br/2009/02/17/casa-da-acolhida-marista-de-uberaba/> . Acesso em: 18 jun. 2010.

MEIRELLES, Z. V.; RUZANY, M. H. Promoçáo de Saúde e Protagonismo Juvenil. In: BRASIL. Ministério da Saúde. Secretaria de Atenção À Saúde. Departamento de Açôes Programáticas Estratégicas. Saúde do adolescente: competências e habilidades. Brasília: Editora do Ministério da Saúde, 2008. cap. 1, p. 35-40.

ZAGURY, T. O adolescente por ele mesmo. 11. ed. Rio de Janeiro: Record, 2000.

\section{Contribuição dos Autores}

Flávia Zago realizou a pesquisa, sob orientação de Ana Cláudia Bredariol e co-orientação de Danielisson Mesquita. Todos os autores são responsáveis pela redação e revisão do manuscrito.

\section{Notas}

${ }^{1}$ A presente pesquisa foi aprovada pelo Comitê de Ética em Pesquisa em Seres Humanos da Universidade de Uberaba sob parecer CAAE - 0034.0.227.000-10. 